\title{
La potestad sancionadora municipal y su relación con la ley en el sistema constitucional mexicano
}

\author{
Manuel Jiménez Dorantes* \\ Doctor en Derecho por la Universidad Autónoma de Madrid. Profesor titular de Derecho \\ Administrativo y Municipal de la Universidad Autónoma de Chiapas, México
}

Sumario: A. PLANTEAMIENTO. - B. POTESTAD NORMATIVA Y RÉGIMEN SANCIONADOR MUNICIPALES. I. La potestad normativa como elemento de la autonomía municipal y su relación con la ley. II. Ejercicio normativo de la potestad sancionadora municipal y reserva de ley.-C. BREVES REFLEXIONES SOBRE EL RÉGIMEN SANCIONADOR MUNICIPAL EN LA REFORMA CONSTITUCIONAL, DE 18 DE JUNIO DE 2008, SOBRE SEGURIDAD Y JUSTICIA. I. Sobre la concurrencia en materia de Seguridad Pública y su relación con el régimen sancionador municipal. II. Ampliación constitucional de las figuras de sanción municipal.-D. BIBLIOGRAFÍA.

\section{A. PLANTEAMIENTO}

La capacidad del Estado para castigar a los particulares es uno de los principales elementos de intervención pública destinados a garantizar algunos bienes o valores que requieren protección (paz, seguridad, orden, etc.) por parte de las autoridades. En este sentido, los órganos del Estado que ejercen funciones administrativas tienen entre sus múltiples objetivos los de proteger y promover el interés general. Para ello, el ordenamiento jurídico ha implementado una serie de mecanismos para que dichos órganos tengan posibilidades de castigar a cualquier sujeto que haya trasgredido el ordenamiento jurídico-administrativo.

Ahora bien, la estructura territorial del Estado mexicano y de sus Entidades federativas, hace necesario analizar rigurosamente el alcance de la capacidad de castigo de los Municipios. En este sentido, los Municipios tienen atribuida constitucionalmente la potestad de sancionar conductas que trasgredan el ordenamiento jurídico municipal, de tal forma, que los Municipios como entidades jurídico-públicas de carácter territorial del Estado mexicano tienen atribuida el ejercicio de una parte del ius puniendi ${ }^{1}$ del Estado para perseguir y castigar conductas que transgredan su propio subsistema normativo.

\footnotetext{
* Este trabajo se desarrolló en el marco del proyecto de investigación de la 7. ${ }^{\text {a }}$ Convocatoria SIINV-UNA$\mathrm{CH}$, denominado «Diferenciación y subsidiariedad en los sistemas jurídicos de ordenamiento territorial y urbanístico», que el autor dirigió en el Cuerpo Académico de Derecho Administrativo y Municipal de la Universidad Autónoma de Chiapas, México, durante el bienio 2007-2008. Agradezco las acertadas observaciones al borrador de este texto que realizó del profesor Dr. Miguel Beltrán de Felipe, de la Universidad de Castilla-La Mancha y miembro externo de dicho Cuerpo Académico.

1 La otra parte reside especialmente en el Derecho penal. Al respecto, el Pleno de la Suprema Corte de Justicia de la Nación, en adelante SCJN, expresa que «tanto el derecho penal como el derecho administrativo sancionador resultan ser dos inequívocas manifestaciones de la potestad punitiva del Estado, entendida
} 
En términos generales, el ordenamiento jurídico prevé mecanismos para reaccionar frente a las actuaciones que violen las determinaciones previstas en las normas -en este caso municipales- y castigar al sujeto que haya realizado la conducta antijurídica determinada en las mismas. Por lo que ahora interesa, la potestad sancionadora de los Municipios se desarrolla en el marco constitucional que condiciona su ejercicio a algunos principios previstos en la Norma fundamental (competencia, proporcionalidad, tipicidad, debido proceso, entre otros).

Este trabajo tiene como objetivo, someter al análisis sistemático ${ }^{2}$ el funcionamiento y alcances de la potestad sancionadora municipal y determinar la intensidad de las relaciones que las normas municipales tienen con la ley. A través del análisis de las determinaciones constitucionales, legales y -en el «diálogo recíproco» que menciona K. LARENZ ${ }^{3}$ - algunas de las resoluciones judiciales más relevantes, se busca delimitar el espacio de autonormación municipal para regular su sistema de infracciones y sanciones. Asimismo, aportar algunas reflexiones teóricas que sean útiles para consolidar el Derecho administrativo sancionador en México que ha tenido una fuerte dependencia del Derecho penal. Ya que, desde la teoría ${ }^{4}$ y las resoluciones jurisdiccionales ${ }^{5}$ se constata el

como la facultad que tiene éste de imponer penas y medidas de seguridad ante la comisión de ilícitos». Novena época, Pleno, Semanario Judicial de la Federación y su gaceta, XXIV, agosto, 2006, pág. 1565, tesis P./J. 99/2006, IUS: 174488. En el mismo sentido, Novena época, Pleno, Semanario Judicial de la Federación y su Gaceta, XXIV, agosto, 2006, pág. 1667, tesis P./J. 100/2006, IUS: 174326.

2 Sobre el método sistémico ver, entre otros, la obra general de LARENZ, Karl, Metodología de la Ciencia del Derecho, 2. a edición, Barcelona, Ariel, 2001, págs. 435 a 482. En especial sobre el Derecho administrativo, remito a la obra de SCHMIDT-ASSMANN, Eberhard, La teoría general del Derecho administrativo como sistema, Madrid, Marcial Pons, 2003, págs. 1 a 15, especialmente.

3 El mismo LARENZ expone la necesaria intercomunicación que se produce entre la teoría y la praxis jurídica: op. cit. págs. 226-231.

4 Un de las diferencias más importantes entre el Derecho penal y el Derecho administrativo sancionador consiste en el concepto de «actividad de policía» para garantizar, mantener y reponer la normalidad del «buen» orden público o buen estado de la cosa común como expuso Otto Mayer. Al respecto ver la exposición de Adolfo PosadA, Tratado de Derecho administrativo. Según las teorías filosóficas y la legislación positivas, 2. ${ }^{\text {e }}$ ed., t. I, Madrid, General Victoriano Suárez, 1923, págs. 292 a 299. En el modelo mexicano, GóNGORA PIMENTEL, Genaro David, «El reconocimiento del Derecho administrativo sancionador en la jurisprudencia constitucional mexicana», en La Ciencia del Derecho procesal constitucional. Estudios en homenaje a Héctor Fix-Zamudio en sus cincuenta años como investigador del Derecho. Ministerio Público, Contencioso administrativo y actualidad jurídica, Ferrer Mac-Gregor, Eduardo y Zaldívar Lelo de Larrea, Arturo (coords.), t. XII, México, UNAM/Marcial Pons/IMDPC, 2008, págs. 257 a 263. En un sentido tendente a garantizar un ámbito diferenciador del Derecho administrativo sancionador respecto del Derecho penal, RoLDÁn XoPA, José, Derecho administrativo, México, Oxford, 2008, págs. 388 a 391. Una exposición sobre la teoría del «Derecho penal administrativo» la realizó MERKL, en Teoría general del Derecho administrativo, Granada, Comares, 2004, págs. 340 a 356.

5 Por ejemplo, menciona el Pleno de la SCJN que «la sanción administrativa guarda una similitud fundamental con las penas, toda vez que ambas tienen lugar como reacción frente a lo antijurídico; en uno y otro supuesto la conducta humana es ordenada o prohibida [...] dada la similitud y la unidad de la potestad punitiva, en la interpretación constitucional de los principios del derecho administrativo sancionador puede acudirse a los principios penales sustantivos...». Novena época, Pleno, Semanario Judicial de la Federación y su Gaceta, XXIV, agosto, 2006, pág. 1565, tesis: P./J. 99/2006, IUS: 174488. Asimismo, el mismo Pleno del Alto tribunal mexicano ha mencionado que debido a esa unidad del ius puniendi estatal, «debe acudirse al aducido principio de tipicidad, normalmente referido a la materia penal, haciéndolo extensivo a las infracciones y sanciones administrativas...». Novena época, Pleno, Semanario Judicial de la Federación y su 
traslado de la estructura y principios del Derecho penal al Derecho administrativo sancionador, lo cual, no ha permitido que éste último haya ido conformando su propia esencia con la dinámica y diferencia que le corresponde ${ }^{6}$.

\section{B. POTESTAD NORMATIVA Y RÉGIMEN SANCIONADOR MUNICIPALES}

\section{La potestad normativa como elemento de la autonomía municipal y su relación con la ley}

Uno de los elementos fundamentales de la capacidad de dirección política propia con el que cuenta el órgano de autogobierno municipal (Ayuntamiento) consiste en el poder del Municipio para emitir normas jurídicas dirigidas a la ordenación de los asuntos y materias que tiene constitucional o legalmente atribuidas ${ }^{7}$.

Dicho poder normativo propio fortalece la idea de autogobierno municipal $y$, por ende, el de autonomía municipal ${ }^{8}$. No obstante, como comprueba la historia legislativa, política y jurisprudencial mexicana de la mayor parte del siglo XX, la capacidad municipal en México se reducía a una simple autonomía

Gaceta, XXIV, agosto, 2006, pág. 1667, tesis: P./J. 100/2006, IUS: 174326. Además utiliza la misma clasificación de los delitos para las infracciones, ya que en el ámbito del Derecho penal, «tratándose de delitos, donde mejor se han perfilado estos conceptos, motivo por el cual analógicamente debe acudirse a los mismos...». Novena época, Segunda Sala, Semanario Judicial de la Federación y su Gaceta, IX, mayo, 1999,

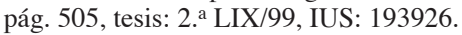

6 No obstante, la mismo Poder Judicial federal ha iniciado una interpretación dirigida a reconocer la separación entre Derecho penal y Derecho administrativo sancionador, por lo que, ha introducido matices a esa dependencia inicial. Por ejemplo, «En diversos precedentes, la Suprema Corte de Justicia de la Nación ha establecido que en el ámbito del derecho administrativo sancionador pueden observarse ciertos principios penales sustantivos, dada la similitud que guarda la pena administrativa con la sanción penal, pero sólo en la medida en que resulten compatibles con su naturaleza jurídica». Novena época, Tribunales Colegiados de Circuito, Semanario Judicial de la Federación y su Gaceta, XXVI, septiembre, 2007, pág. 2542, tesis: I.15o.A 83 A, IUS: 171438 (el subrayado es mío).

7 Por ejemplo, artículo 115, fracción III CF.

8 En el modelo español, a partir de la vigente Constitución de 1978 (CE), se ha venido dando un impulso doctrinal a los alcances de la autonomía local y, por lo que aquí interesa, de la potestad sancionadora de los Municipios. Resulta opinión consolidada que la idea misma de la autonomía local garantizada por artículos 137 y $140 \mathrm{CE}$, lleva implícita la posibilidad sancionadora de las entidades locales para hacer efectivas sus decisiones sobre los asuntos que tiene bajo su responsabilidad. En consecuencia, los Municipios tienen características específicas que permiten la flexibilización o matización de los principios de legalidad y de reserva de ley. Por ejemplo, el origen y legitimidad democrática del órgano de gobierno municipal y su consecuente influencia sobre la reserva de ley, así como, la distribución territorial del poder. Por lo que, dicha potestad normativa de los municipios es algo más que la simple ejecución de la ley ya que tiene un ámbito propio de regulación. Además, a diferencia del modelo mexicano, la misma CE impide la posibilidad de sanciones privativas de libertad (artículo $25 \mathrm{CE}$ ). En este sentido, ver: J.L. Carro Fernández-Valmayor, «Sobre la potestad sancionadora municipal», Cuadernos de Derecho Local, No. 6, octubre, 2004, Madrid, págs. 132 a 136. Nieto, Alejandro, Derecho administrativo sancionador, 4. ${ }^{a}$ ed., Madrid, Civitas, 2005, págs. 17-18 y 201296. Toscano Gil, Francisco, Autonomía y potestad normativa local, Sevilla, Comares, 2006, págs. 73 y ss. Rivero Ysern, José Luis, Manual de Derecho local, 5. a ed., Madrid, Thomson-Civitas, 2003, págs. 74 a 77. Velasco Caballero, Francisco y Díez Sastre, Silvia, «Ordenanzas municipales y reserva de ley sancionadora», Cuadernos de Derecho Local, No. 5, junio, 2004, págs. 50 a 62, entre otros. 
administrativa que implicó una tutela o control sobre la capacidad de autogestión municipal, ya que, su participación se redujo a la ejecución o aplicación de las leyes, lo que, a todas luces, ubicó a los Municipios en franca subordinación frente a las determinaciones legales y ejecutivas de la Entidad federativa ${ }^{9}$.

En este orden de ideas, en el concreto ámbito de su capacidad para normar los asuntos propios, los Municipios encontraron un enorme límite a su poder no sólo normativo sino de autogobierno, ya que, se entendió que el poder normativo que ejercían los Municipios a través de su Ayuntamiento se reducía a la emisión de normas reglamentarias que -como tales- quedaban sujetas a la idea liberal sobre la relación jerárquica de las normas que se produce entre la ley del Poder legislativo con el reglamento del Presidente (en el modelo federal) o Gobernador de cada Entidad federativa.

Al respecto, la doctrina y resoluciones judiciales en México, entendieron que la potestad normativa municipal estaba jerárquicamente sometida y subordinada a la legislación. Desde la reforma del artículo 115, fracción II, a la Constitución federal (en adelante CF), de 3 de febrero de 1983 y hasta la reforma de diciembre 1999, se dio una interpretación constitucional restrictiva del artículo 115, ya que, se entendía que la potestad normativa municipal se ejercía de acuerdo con las normas que, para el efecto, aprobaban los respectivos Congresos estatales, de tal forma que, la reforma de 3 de febrero de 1983, «sujeta a tales reglamentos [autónomos], así como a los bandos de policía y buen gobierno, a las bases normativas que deben establecer las legislaturas de los Estados» ${ }^{10}$. Por ende, se consolidó la total subordinación de las normas municipales a la ley y que -según el Pleno de la Suprema Corte de Justicia de la Nación, en adelante SCJN - esta limitación a la función normativa municipal se refería a que: «1) No pueden estar en oposición a la Constitución General ni a las de los Estados, así como tampoco a las leyes federales o locales; 2) En todo caso, debe adecuarse a las bases normativas que emitan las Legislaturas de los Estados; y, 3) Deben versar sobre materias o servicios que le correspondan legal o constitucionalmente a los Municipios» ${ }^{11}$.

Esta comprensión de la potestad normativa municipal implicó que la facultad para emitir normas jurídicas estaba vinculada en todo momento a la ley (federal

\footnotetext{
9 En la historia constitucional mexicana el control sobre la actuación municipal ha sido una constante. Por ejemplo, el artículo 14 de la Constitución de 1836, determinaba que correspondía a las autoridades supralocales formar las ordenanzas de los Ayuntamientos y los reglamentos. Las Bases orgánicas de la República, de 12 de junio de 1843, determinaron que las Asambleas departamentales, eran competentes para expedir las ordenanzas respectivas y reglamentar la policía municipal urbana y rural, así como los presupuestos municipales. En este sentido, ver la respuesta del órgano reformador de la Constitución federal de 1917 a la reforma del artículo 115, de 23 de diciembre de 1999, para destacar a los Ayuntamientos como un auténtico nivel de gobierno encargado en exclusiva de los asuntos locales.

10 Octava época, Segundo Tribunal Colegiado del Sexto Circuito, Semanario Judicial de la Federación y su Gaceta, XIII, junio, 1994, pág. 652, tesis: XVI.2. ‥37. a , IUS: 212368

11 Ver, Novena época, Pleno, Semanario Judicial de la Federación y su gaceta, XV, enero, 2002, tesis: P./J. 132/2001, pág. 1041, IUS: 187983.
} 
o estatal), de manera que, a mi juicio equivocadamente, todas las normas municipales funcionaban bajo el esquema jerárquico (ley + reglamento de desarrollo ${ }^{12}$ ) que -como se ha expuesto- caracterizan a la facultad reglamentaria del Presidente o Gobernador (primacía de ley y carácter secundario del reglamento) ${ }^{13}$.

No obstante, esta forma de entender la potestad normativa de los Municipios, sencillamente se aleja de la idea central del régimen municipal. Ya que, no es adecuado aplicar a la relación normativa municipal teorías que han sido diseñadas y desarrolladas para razones y dinámicas totalmente distintas. Es decir, la relación jerárquica que se produce entre la ley y el reglamento presidencial o gubernamental opera en razón de la división o distribución de poderes, en el que, el ejercicio de la potestad reglamentaria del Poder ejecutivo (sea federal o estatal) queda subordinada en todo momento a la ley. Por ello, resulta ejemplificativo en el modelo federal que el artículo 89, fracción I CF, condiciona a la existencia de una ley previa para su ejercicio en vertiente normativa (reglamentaria).

En consecuencia, resulta doctrina mexicana consolidada que no existe reglamento sin ley, por lo que la ley es el requisito sine qua non para el ejercicio de la potestad reglamentaria ${ }^{14}$. De tal forma, adquiere sentido la idea de que la facultad reglamentaria del Presidente encuentra límites (formales, materiales y de contenido) en la facultad legislativa del Congreso federal. Al respecto, el Pleno de la SCJN ha afirmado que la facultad reglamentaria presidencial en-

12 La cuestión básica consiste en que el reglamento está subordinado a la ley y «suelen designarse reglamentos ejecutivos, porque sirven para concretar más al detalle el contenido de una ley ordinaria...»: A. Merkl, ob. cit., pág. 155. Asimismo, Posada expone que «1. ${ }^{\circ}$ Un reglamento no puede modificar las disposiciones de las leyes; $2{ }^{\circ}$ Un reglamento no puede violar los derechos fundamentales...». ob. cit., pág. 240.

13 Sobre la relación ley-reglamento ver la exposición de SANTAMARÍA PASTOR, Juan Alfonso, Principios de Derecho administrativo general, t. I, Madrid, Iustel, 2005, págs. 322 a 330. En el ámbito mexicano, ver el estudio de CASARÍn LEÓN, Manlio Fabio, La facultad reglamentaria, México, Porrúa-UV, 2003, págs. 57 a 122, especialmente. También LóPEZ OLVERA, Miguel Alejandro, Tratado de la facultad reglamentaria, México, Porrúa, 2007, págs. 96 a 112.

14 El artículo 49 de la Constitución federal lleva a cabo excepciones puntuales al principio de división de poderes, ya que permite que el Poder legislativo pueda depositarse en el Presidente de la República para que -en ejercicio de sus facultades «legislativas» extraordinarias- emita normas con rango de ley en casos tasados (artículos 29 «suspensión de garantías individuales» y 131 «materia arancelaria» CF). Sobre el artículo 49 CF la Sala Segunda del Alto tribunal mexicano ha expuesto «que la prohibición contenida en el referido numeral, relativa a que el Poder Legislativo no puede depositarse en un individuo, conlleva que en ningún caso, salvo lo previsto en los artículos 29 y 131 de la propia Norma Fundamental, un órgano del Estado diverso al Congreso de la Unión o a las Legislaturas Locales, podrá ejercer las atribuciones que constitucionalmente les son reservadas a éstos, es decir, la emisión de los actos formalmente legislativos, por ser constitucionalmente la fuente primordial de regulación respecto de las materias que tienen una especial trascendencia a la esfera jurídica de los gobernados, deben aprobarse generalmente por el órgano de representación popular». Novena época, Segunda Sala, Semanario Judicial de la Federación y su Gaceta, XVI, diciembre, 2002, pág. 239, tesis: 2. a/J. 143/2002, IUS: 185404, entre otras. Se ha dicho que las normas derivadas de la facultad extraordinaria para legislar del Presidente, «que tengan la misma jerarquía que una ley proveniente del Congreso de la Unión, no implica una afectación al principio de división de poderes contenido en el artículo 49 de la Constitución Federal, pues ésta no reproduce una teoría rígida de dicho principio, sino una división flexible que da lugar a una colaboración entre los Poderes de la Unión». Novena época, Primera Sala, Semanario Judicial de la Federación y su Gaceta, XXVI, septiembre, 2007, pág. 376, tesis: $1 .^{\mathrm{a}} \mathrm{CC} / 2007$, IUS: 171522. 
cuentra límites en los principios de reserva de ley y subordinación jerárquica, el de reserva de ley, "se presenta cuando una norma constitucional reserva expresamente a la ley la regulación de una determinada materia, por lo que excluye la posibilidad de que los aspectos de esa reserva sean regulados por disposiciones de naturaleza distinta a la ley, esto es, por un lado, el legislador ordinario ha de establecer por sí mismo la regulación de la materia determinada y, por el otro, la materia reservada no puede regularse por otras normas secundarias, en especial el reglamento. [...] el de jerarquía normativa, consiste en que el ejercicio de la facultad reglamentaria no puede modificar o alterar el contenido de una ley, es decir, los reglamentos tienen como límite natural los alcances de las disposiciones que dan cuerpo y materia a la ley que reglamentan, detallando sus hipótesis y supuestos normativos de aplicación, sin que pueda contener mayores posibilidades o imponga distintas limitantes a las de la propia ley que va a reglamentar. Así, el ejercicio de la facultad reglamentaria debe realizarse única y exclusivamente dentro de la esfera de atribuciones propias del órgano facultado, pues la norma reglamentaria se emite por facultades explícitas o implícitas previstas en la ley o que de ella derivan, siendo precisamente esa zona donde pueden y deben expedirse reglamentos que provean a la exacta observancia de aquélla, por lo que al ser competencia exclusiva de la ley la determinación del qué, quién, dónde y cuándo de una situación jurídica general, hipotética y abstracta, al reglamento de ejecución competerá, por consecuencia, el cómo de esos mismos supuestos jurídicos. En tal virtud, si el reglamento sólo funciona en la zona del cómo, sus disposiciones podrán referirse a las otras preguntas (qué, quién, dónde y cuándo), siempre que éstas ya estén contestadas por la ley; es decir, el reglamento desenvuelve la obligatoriedad de un principio ya definido por la ley y, por tanto, no puede ir más allá de ella, ni extenderla a supuestos distintos ni mucho menos contradecirla, sino que sólo debe concretarse a indicar los medios para cumplirla y, además, cuando existe reserva de ley no podrá abordar los aspectos materia de tal disposición» 15 .

Asimismo, el ejercicio de la facultad reglamentaria del Presidente (artículo 89, fracción I CF), se ejerce "para expedir normas reglamentarias de las leyes emanadas del Congreso de la Unión, y aunque desde el punto de vista material ambas normas son similares, aquéllas se distinguen de éstas, básicamente, en que provienen de un órgano que al emitirlas no expresa la voluntad general, sino que está instituido para acatarla en cuanto dimana del Legislativo, de donde, por definición, son normas subordinadas, de lo cual se sigue que la facultad reglamentaria se rige por dos principios: el de reserva de ley y el de subordinación jerárquica a la misma. El principio de reserva de ley que encuentra su justificación en la necesidad de preservar los bienes jurídicos de mayor valía de los gobernados (tradicionalmente libertad personal y propiedad), prohíbe

15 Novena época, Pleno, Semanario Judicial de la Federación y su Gaceta, XXV, mayo, 2007, pág. 1515, tesis: P./J. 30/2007, IUS: 172521. 
que en el reglamento se aborden materias reservadas en exclusiva a las leyes del Congreso, como son las relativas a la definición de los tipos penales, las causas de expropiación y la determinación de los elementos de los tributos, mientras que el principio de subordinación jerárquica, exige que el reglamento esté precedido por una ley cuyas disposiciones desarrolle, complemente o pormenorice y en las que encuentre su justificación y medida» ${ }^{16}$.

En el caso de la potestad normativa municipal, la cuestión no tiene que ver con la teoría de la división horizontal del poder público, sino que la explicación a la facultad para emitir normas municipales proviene del principio de distribución territorial del poder público (competencia) y del principio de autonomía municipal. De manera que la cuestión no radica en la división de poderes o funciones sino en la autonomía de los Municipios para llevar a cabo su propia normación sobre las materias o asuntos que tanto la Constitución como la ley le han otorgado para ejercer en régimen de autonomía (principio de competencia).

Al respecto, la $\mathrm{CF}$ ha habilitado a los Municipios para ejercer la potestad normativa necesaria en su régimen de autonomía y otorga a los Municipios la posibilidad de regular u ordenar los asuntos que las Constituciones (federal y estatal) y las leyes (federales y estatales) encomiendan a los entes municipales. De lo contrario, el Ayuntamiento carecería de uno de sus elementos más importantes para regular u ordenar aquéllos asuntos o materias que tiene atribuidas para ejercer bajo su propia responsabilidad y atendiendo a sus particularidades de cada Municipio, cuestiones específicas y diferenciadas que, evidentemente, no tiene posibilidades de prever el legislador.

La modificación constitucional de 1999 incidió en los alcances que sobre la autonomía municipal había llevado a cabo la SCJN, ya que sobre dicha reforma del artículo 115 se expuso que «los Ayuntamientos pueden expedir dos tipos de normas reglamentarias: a) el reglamento tradicional de detalle de las normas, que funciona similarmente a los derivados de la fracción I del artículo 89 de la Constitución Federal y de los expedidos por los Gobernadores de los Estados, en los cuales la extensión normativa y su capacidad de innovación está limitada, pues el principio de subordinación jerárquica exige que el reglamento esté precedido por una ley cuyas disposiciones desarrolle, complemente o pormenorice y en las que encuentre su justificación y medida; y b) los reglamentos derivados de la fracción II del artículo 115 constitucional, que tienen una mayor extensión normativa, ya que los Municipios, respetando las bases generales establecidas por las legislaturas, pueden regular con autonomía aquellos aspectos específicos de la vida municipal en el ámbito de sus competencias, lo cual les permite adoptar una variedad de formas adecuadas para regular su vida interna, tanto en lo referente a su organización administrativa y sus com-

16 Novena época, Primera Sala, Semanario Judicial de la Federación y su Gaceta, XXVI, septiembre, 2007, pág. 122, tesis: 1. a/J. 122/2007, IUS: 171459 (destacado mío). 
petencias constitucionales exclusivas, como en la relación con sus gobernados, atendiendo a las características sociales, económicas, biogeográficas, poblacionales, culturales y urbanísticas, entre otras, pues los Municipios deben ser iguales en lo que es consustancial a todos -lo cual se logra con la emisión de las bases generales que emite la Legislatura del Estado-, pero tienen el derecho, derivado de la Constitución Federal de ser distintos en lo que es propio de cada uno de ellos, extremo que se consigue a través de la facultad normativa exclusiva que les confiere la citada fracción $I I »{ }^{17}$.

Desde mi perspectiva, la CF no limita -en todos los casos- la capacidad normativa de los Municipios a la existencia previa de la ley. Esta visión representa una salida simple a través de la relación entre Poder legislativo y Poder ejecutivo derivado del modelo liberal, que se desentiende del sentido mismo de la autonomía constitucionalmente garantizada a los Municipios mexicanos. De manera que aún no se ha delineado con la debida claridad la intensidad de la vinculación de la regulación municipal al conjunto del entramado legislativo (federal y estatal); la interpretación de la SCJN en este aspecto confirma el «vínculo» entre la norma municipal y la ley en materia municipal, al determinar que las bases que dictan las Entidades federativas resultan plenamente obligatorias para los Municipios.

Si como se ha advertido, la cuestión sobre la potestad normativa de los $\mathrm{Mu}-$ nicipios opera en el nivel de distribución competencial y de autonomía municipal, entonces resulta preceptivo advertir que la relación entre ley y norma municipal encuentra diversas expresiones de relación cuya intensidad está determinada por la misma Constitución. Aunque -como se verá- el desarrollo legislativo y jurisprudencial presenta resistencias a incrementar las posibilidades normativas de los Municipios, como ya he dicho en otro lugar ${ }^{18}$, es indispensable reconocer que los Municipios tienen posibilidades para regular ciertos asuntos sin necesidad de existencia previa de ley (reserva de norma municipal). En consecuencia, en algunas materias o asuntos municipales la norma municipal funcionaría como una especie de «ley» (lato sensu) directamente aplicable en el subsistema normativo municipal, ya que su existencia autónoma vendría habilitada directamente de la CF (artículos 21 y 115).

Sin embargo, la interpretación al respecto aún resulta insuficiente para el régimen municipal, de ahí que se haya aclarado que la reforma de 1999 al artículo 115 fracción II CF, «buscó establecer un equilibrio competencial en el que prevaleciera la regla de que un nivel de autoridad no tiene

\footnotetext{
17 Novena época, Pleno, Semanario Judicial de Federación y su Gaceta, XXII, octubre, 2005, pág. 2069, tesis: P./J. 132/2005. IUS: 176929.

18 JimÉnEz Dorantes, Manuel, Autonomía municipal y planeamiento urbanístico, México, Fontamara, 2007 , págs. 81 y 82 . Al respecto recientemente se insiste que «para evitar inconsistencias en el ordenamiento tiene que admitirse junto con la existencia de los reglamentos autónomos que para su eficacia es válido que desempeñen ciertas funciones de la ley». Roldán Xopa, José, ob. cit., pág. 125.
} 
facultades mayores o más importantes que el otro, sino un esquema en el que cada uno tenga las atribuciones que constitucionalmente le corresponden; de manera que al Estado compete sentar las bases generales a fin de que exista similitud en los aspectos fundamentales en todos sus Municipios, y a éstos corresponde dictar sus normas específicas, dentro de su jurisdicción.... ${ }^{19}$.

En primer lugar, los asuntos o materias exclusivamente municipales representan el núcleo duro de la autonomía municipal y de su enorme ámbito de regulación propia según las necesidades específicas de cada Municipio. En este caso, el legislador está limitado en su capacidad, ya que la legislación sobre asuntos que la misma CF reserva en exclusividad a los Municipios implicaría la invasión del espectro competencial municipal (especialmente las materias del artículo 115, fracción III CF), ámbito este en el cual a mi juicio el Municipio puede desarrollar su capacidad normativa sin que exista ley previa (reserva de norma municipal) ${ }^{20}$.

Ahora bien, cabe la posibilidad de considerar que la misma CF determina que el legislador tiene habilitación para introducirse en el régimen normativo municipal al establecer las bases municipales. No obstante, dicha legislación estatal encuentra límite en la autonomía municipal, por lo que su legislación debe mantener un margen de libre regulación a los Municipios. Es decir, como la misma CF determina claramente, las bases del legislador estatal sobre materia municipal únicamente deben referirse a cuestiones esenciales pero en ningún caso llevar a cabo regulación sobre la materia o asunto con exhaustividad o de contenido pormenorizado que impida a los Municipios la posibilidad de ordenar en régimen de autonomía y de acuerdo a sus características las particularidades de la materia objeto de ordenación.

A partir de la reforma constitucional de 23 de diciembre de 1999, la CF determina en el art. 115, fracción II, la posibilidad de que la Entidad federativa apruebe las «leyes estatales en materia municipal» que determinan las bases procedimentales para el ejercicio de la potestad normativa municipal. La razón que lo explica consiste en la decisión constitucional de que corresponda a cada una de las Entidades federativas la regulación de las bases municipales atendiendo a las características propias de sus Municipios, de manera que en cada Entidad federativa se produzca un contenido normativo mínimo o esencial en todos los Municipios, pero a su vez, el propio legislador estatal tiene el deber

19 Novena época, Pleno, Semanario Judicial de la Federación y su Gaceta, XXII, octubre, 2005, pág. 2068, tesis: 133/2005, IUS: 176948. Se puede consultar también, Novena época, Segunda Sala, Semanario Judicial de la Federación y su Gaceta, XXVII, mayo 2008, pág. 71, tesis: 2a./J. 82/2008, IUS: 169690.

20 Con toda claridad y contundencia Caamaño menciona que: «Sólo la idea de autonomía local subordinada a la ley puede negar, desde esta óptica asociada a las fuentes de producción normativa, la condición política que le es inherente. Ahora bien, una autonomía local subordinada al legislador no es, en puridad, autonomía». CAAMAÑo Domínguez, Francisco, «Autonomía local y Constitución. Razones para recuperar la causalidad perdida», Anuario del Gobierno Local 2003, Madrid, 2003, pág. 54. 
constitucional de respetar la diversidad que se produce entre los Municipios de su Entidad federativa para que sean éstos los que, atendiendo a sus complejas características y diversidades, puedan precisar su régimen de autoorganización, participación ciudadana, control de su actuación, entre otros.

En este orden de ideas, según el artículo 115, fracción II e) CF, también las «bases» municipales dictadas por el legislador estatal funcionan como regulación esencial en aquéllos casos en que algún Municipio de su Estado no cuenta con sus propias normas municipales, de tal forma, que ante la ausencia de regulación municipal de los asuntos locales, de forma subsidiaria, se completaría mediante la aplicación temporal y directa de las bases estatales ${ }^{21}$. Evidentemente, al tratarse de un asunto municipal, cuando el Ayuntamiento dicte su propia normativa las bases se posicionan como norma orientadora de las «nuevas» normas municipales y éstas desplazan a un segundo plano a las bases estatales.

Esta determinación constitucional incide directamente en los alcances de la autonomía municipal, especialmente en su vertiente normativa, ya que posibilita al legislador estatal regular los aspectos básicos o generales municipales o para aquellos casos en que no existen reglamentos municipales.

Queda así de manifiesto que la misma CF ha intentado limitar los alcances de la legislación estatal, reduciéndola a la regulación (básica) «a fin de potenciar la capacidad reglamentaria de los Ayuntamientos», por lo que sólo pueden referirse a la organización administrativa municipal, procedimiento administrativo, medios de impugnación, decisiones que perjudiquen el patrimonio inmobiliario municipal o comprometan al Municipio por un período más amplio de un gobierno municipal así como las normas básicas para celebrar convenios con el Estado. Al respecto, la SCJN ha evolucionado en un tratamiento menos restrictivo sobre la potestad normativa municipal, ya que «los Municipios tendrán que respetar el contenido de esas bases generales al dictar sus reglamentos, pues lo establecido en ellas les resulta plenamente obligatorio por prever un marco que da uniformidad a los Municipios de un Estado en aspectos fundamentales, el cual debe entenderse como el caudal normativo indispensable que asegure el funcionamiento del Municipio, sin que esa facultad legislativa del Estado para regular la materia municipal le otorgue intervención en las cuestiones específicas de cada Municipio, toda vez que ello le está constitucionalmente reservado a este último» ${ }^{22}$.

21 En este sentido ver, Novena época, Pleno, Semanario Judicial de la Federación y su Gaceta, XXII, octubre, 2005, pág. 2065, tesis: P./J. 131/2005, IUS: 176951.

22 Novena época, Pleno, Semanario Judicial de la Federación y su Gaceta, t. XXII, octubre, 2005, pág. 2067, tesis: P./J. 129/2005 (registro: 176949). En este mismo sentido, la SCJN expone que «al Estado compete sentar las bases generales a fin de que exista similitud en los aspectos fundamentales en todos sus Municipios, y a éstos corresponde dictar sus normas específicas, dentro de su jurisdicción, sin contradecir esas bases generales». Novena época, Pleno, Semanario Judicial de la Federación y su Gaceta, XXII, octubre, 2005, pág. 2068, tesis: P./J. 133/2005, IUS: 176948. 
Como suele suceder en estos casos en los que se recurre a la solución de lo «básico» o «bases», siempre queda en manos del legislador la posibilidad de determinar los alcances de su actuación partiendo de lo que considera «básico», de ahí la necesidad de control por parte de la jurisdicción constitucional. En este orden de ideas, es claro el riesgo que para la autonomía municipal implica que el legislador decida sobre asuntos relevantes para la protección municipal como las bases a las que deben sujetarse los convenios entre Municipio y Entidad federativa, o que el Congreso estatal determine los casos en que el Municipio está «imposibilitado» para ejercer o prestar sus funciones o servicios atribuidos, así como el procedimiento y condiciones en que la Entidad federativa asuma las funciones municipales y, también, las normas aplicables para resolver conflictos entre Municipios y con el Gobierno del Estado ${ }^{23}$.

Antes de pasar al segundo caso sobre materias con facultades concurrentes, conviene proponer algunas ideas para determinar en alguna medida la característica de las leyes municipales de contenido básico o general.

En este sentido, el legislador estatal es el competente en materia municipal pero dicha competencia legislativa viene limitada directamente por los principios de autonomía municipal, competencia y diversidad municipal, entre otros. De tal forma que la facultad legislativa en materia municipal de la Entidad federativa no es total, ya que no tiene posibilidades de regular dicha materia en toda su extensión y detalle, sino que su objetivo consiste en llevar a cabo una regulación esencial u orientadora para el adecuado funcionamiento de todos los Municipios (uniformidad) y, especialmente para aquéllos que no cuentan con su propia normatividad (subsidiariedad).

Asimismo, la ley estatal en materia municipal -como indican las resoluciones judiciales mencionadas- contiene las bases o aspectos esenciales que, por efecto de la autonomía municipal constitucionalmente garantizada, debe ser desarrollada y pormenorizada por los instrumentos normativos de cada uno de los Municipios atendiendo a sus características, necesidades y conformaciones políticas propias. De ahí que, respecto a la densidad normativa, la ley estatal en materia municipal tiene límites de contenido y directivos, ya que, únicamente, su alcance constitucionalmente determinado está referido a las cuestiones generales o básicas para permitir un espacio o margen de autorregulación municipal propio y diferenciado.

En el segundo caso, el sistema de distribución competencial se refiere a las facultades concurrentes (urbanismo, medio ambiente, deporte, turismo, entre muchas otras), en las que la Federación, las Entidad federativa y los Municipios tienen constitucionalmente garantizada su intervención a través de sus respectivas competencias (normativas y ejecutivas). Evidentemente, el carácter concurrente de la materia implica, por un lado, permitir al legislador regular la

23 Art. 115, fracción II CF. 
materia para permitir una acción coordinada del resto de entidades territoriales. Por el otro, implica también un límite al mismo legislador porque la autonomía municipal «debilita» el principio de reserva de ley y fortalece el de potestad normativa municipal, ya que la potestad municipal consiste en la aprobación de normas dirigidas a la ejecución de la leyes de materias concurrentes y, a la vez, en la aprobación de normas municipales que puedan ampliar o complementar las determinaciones previstas en las leyes estatales.

\section{Ejercicio normativo de la potestad sancionadora municipal y reserva de ley}

Como se ha dicho, los Municipios tienen atribuida constitucionalmente la potestad normativa y, además, la potestad sancionadora. En este momento, importa exponer las reflexiones sobre la regulación de la potestad sancionadora de los Municipios en sus diversas normas jurídicas ${ }^{24}$. En consecuencia, los Municipios tienen posibilidades para introducir directamente en su reglamentación ( sin necesidad de habilitación legal) diversas infracciones y sanciones a conductas que considere necesarias sobre los asuntos que le han sido encomendados por las Constituciones (federal y estatal) en régimen de exclusividad. De manera que, por efecto de su autonomía, los Municipios pueden ejercer su potestad sancionadora sobre sus asuntos propios sin que esta posibilidad implique la ruptura del principio de legalidad o de reserva de ley ya que, el concepto mismo de autonomía municipal implica que en las normas municipales (especialmente los reglamentos, bandos gubernativos y de policía) cabe la infracción y sanción ${ }^{25}$. De ahí que la potestad sancionadora municipal viene constitucionalmente atribuida aunque, en ocasiones, pueda parecer que es el legislador quien la atribuye ${ }^{26}$.

Además del principio de autonomía municipal también ejerce su influencia el artículo 21 del mismo Texto fundamental, en el cual, desde su redacción original de 1917, se ha habilitado a las autoridades administrativas a castigar las infracciones a los reglamentos gubernativos y de policía. De tal forma que la

\footnotetext{
24 En este caso se deja a un lado otros dos temas esenciales de la potestad sancionadora: «imposición» y «ejecución» de sanciones que requieren otro estudio pormenorizado y que se alejan la idea central de este trabajo sobre la regulación o normación de infracciones y sanciones en el ámbito municipal.

25 La capacidad para determinar sanciones e infracciones administrativas viene limitada por el art. $21 \mathrm{CF}$.

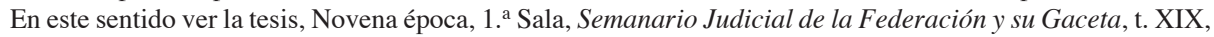
junio, 2004, pág. 242, tesis: 1 . $^{\mathrm{a}}$ LXXIV/2004, IUS: 181271.

26 Por ejemplo, artículo 38, fracción XLII LOMCh, «autoriza» a los Municipios para regular infracciones y sanciones en sus reglamentos. Mientras que, en el modelo veracruzano, su legislación da por sentado los alcances de la autonomía municipal sobre la potestad sancionadora y, simplemente, determina que el Presidente municipal deberá hacer cumplir las normas municipales y «aplicar a los infractores las sanciones correspondientes» (fracción III). "Vigilar que diariamente se califiquen las infracciones a los reglamentos imponiendo en ese acto a los infractores la sanción que les corresponda» (fracción IV), Ley orgánica del Municipio libre de Veracruz.
} 
CF se aleja de la concentración del castigo estatal en los jueces y tribunales, y, al igual que la Constitución mexicana de 1857, reconoce un ius puniendi administrativo y rompe la idea de exclusividad de castigo judicial y distingue entre los asuntos penales con competencia exclusiva de los jueces y tribunales ${ }^{27}$ y los asuntos administrativos con competencia para las autoridades administrativas.

Como ha sido estudiado y expuesto, los Municipios ejercen la función administrativa en el ámbito de sus respectivas competencias sobre su territorio, de tal forma que cada uno de los Municipios tienen habilitación constitucional para normar o regular sus asuntos que ejercen en régimen de exclusividad o, en otros casos, de concurrencia con el resto de entidades jurídico-públicas de carácter territorial. Para ello, el artículo $21 \mathrm{CF}$, pone directamente a disposición de las normas administrativas, entre ellas las municipales, algunos castigos por conductas antijurídicas (infracciones) que prevén sus normas (bandos de policía, bandos de buen gobierno, reglamentos, etcétera): «multa», «arresto hasta por 36 horas» $\mathrm{y}$ «trabajo a favor de la comunidad» ${ }^{28}$.

La razón parece clara, porque la CF ha dotado de autonomía a los Municipios y, en consecuencia, ha determinado expresamente un ámbito de asuntos públicos a su cargo y responsabilidad, para ello, otorga potestad normativa específica y, además, establece un sistema democrático para la conformación del Ayuntamiento (gobierno municipal). Como expone la SCJN, los Municipios cuentan con un «orden jurídico propio» ${ }^{29}$ (un subsistema). De manera que la ordenación de los asuntos municipales y la posible previsión de sanciones administrativas se originan y aprueban en el seno del Ayuntamiento democráticamente elegido por los ciudadanos, algo similar -salvando las distancias- a lo que sucede con el legislador democrático que aprueba las leyes sobre los asuntos que han sido encomendados por la misma CF o, en su caso, estatal.

Ahora bien, la cuestión central consiste en determinar los alcances de la potestad sancionadora municipal sobre la previsión de castigos de la Constitución federal (artículo 21). Es decir: plantearse si para ejercer dicha potestad existe una relación directa Municipio-Constitución Federal, o si por el contrario, los Municipios están nuevamente subordinados a la legislación estatal para establecer infracciones y sanciones a sus normas jurídicas propias.

$\mathrm{Al}$ respecto podemos destacar dos casos. El primero que resulta de la evidencia normativa y jurisdiccional, consiste en que, debido a la subordinación general entre la ley y la normas municipal (bando y reglamento, especialmente), el contenido de las normas municipales sobre régimen sancionador está supeditado a las leyes estatales. Es decir, que los Municipios únicamente tienen

\footnotetext{
27 Artículo 21 párrafo $3{ }^{\circ} \mathrm{CF}$ : «La imposición de las penas, su modificación y duración son propias y exclusivas de la autoridad judicial». Reforma de 18 de junio de 2008.

28 Artículo 21, párrafo $4 .^{\circ} \mathrm{CF}$. Adicionado por reforma constitucional, de 18 de junio de 2008.

29 Novena época, Pleno, Semanario Judicial de la Federación y su Gaceta, XXII, octubre, 2005, pág. 2070, tesis: 134/2005, IUS: 176928.
} 
posibilidades de regular su «propio» régimen sancionador a partir de las determinaciones impuestas por el legislador. En este sentido, cabe destacar que el legislador tiene posibilidades de ampliar el abanico de figuras de castigo del artículo $21 \mathrm{CF}$, de las que puede disponer el Municipio para regular de forma autónoma su régimen sancionador (inhabilitación, suspensión, demolición, destitución, clausura, entre muchas otras). Y, derivado del principio de autonomía, dejar al Ayuntamiento la configuración de infracciones y sus respectivas sanciones a partir de las figuras de castigo previstas en la ley estatal. De este modo, se ha entendido que la limitación de las tres figuras de castigo administrativo previstas en la CF no aplica para el legislador, que puede ampliar las posibilidades de castigo (sanción) ${ }^{30}$. Al respecto resulta representativa la resolución de la Primera Sala de la SCJN: «Cuando las sanciones que imponen las autoridades administrativas tienen como sede reglamentos gubernativos o de policía, éstas sólo podrán consistir en multa o en arresto hasta por treinta y seis horas, en términos del artículo 21 de la Constitución Política de los Estados Unidos Mexicanos; sin embargo, cuando tales sanciones sean impuestas con fundamento en la ley, resulta incuestionable que no pueden constreñirse a la multa o al arresto, sino que válidamente procede la imposición de diversos correctivos, como puede ser el decomiso de mercancías o cualquier otro que contemple la legislación aplicable» ${ }^{31}$.

La segunda tesis que aquí se sostiene consiste en afirmar la posibilidad constitucional de el Ayuntamiento pueda utilizar directamente las figuras de castigo del artículo $21 \mathrm{CF}$, porque la Constitución ha establecido y limitado que las autoridades administrativas puedan utilizar los tipos sancionadores directamente en sus normas administrativas, sin necesidad de existencia previa de ley. Aunque pudiera argumentarse como un exceso de las posibilidades de castigo administrativo, la cuestión ya viene limitada, condicionada o controlada directamente por las tres posibilidades que la misma CF establece (multa, arresto, trabajo comunitario), así como por una serie de principios y subprincipios -también constitucionales- que limitan no sólo al legislador sino también a la potestad sancionadora administrativa, en este caso, municipal (proporcionalidad, debido proceso, juridicidad, seguridad jurídica, control judicial de la Administración, adecuación, entre otros).

De lo contrario, carecería de sentido dotar al Municipio de órgano de gobierno (Ayuntamiento) democráticamente elegido, atribuirle la responsabilidad sobre algunos asuntos públicos, determinar su potestad normativa para ordenar dichos asuntos, dotarlo de capacidad de autoorganización, de financia-

\footnotetext{
30 En este sentido, Novena época, Pleno, Semanario Judicial de la Federación y su Gaceta, V, junio, 1997, pág. 142, tesis: P. XCII/97, IUS: 198414. Sobre la sanción de clausura, mencionó el Pleno que «esa limitación no es aplicable tratándose de infracciones administrativas a las leyes emanadas del Congreso de la Unión, puesto que son ordenamientos legales de naturaleza diferente».

31 Novena época, Semanario Judicial de la Federación y su Gaceta, XIX, junio, 2004, pág. 242, tesis: 1a. LXXIV/2004, IUS: 181271.
} 
miento y de medios constitucionales de defensa (controversia constitucional federal o estatal, especialmente) pero, por otro lado, prohibirle que de manera autónoma pueda ordenar coherentemente dichos asuntos a través del establecimiento de algunas infracciones y sanciones administrativas, subordinándolo a la voluntad del legislador y no a los principios constitucionales que también le rigen.

\section{BREVES REFLEXIONES SOBRE EL RÉGIMEN SANCIONADOR MUNICIPAL EN LA REFORMA CONSTITUCIONAL, DE 18 DE JUNIO DE 2008, SOBRE SEGURIDAD Y JUSTICIA}

\section{Sobre la concurrencia en materia de Seguridad Pública y su relación con el régimen sancionador municipal}

Un último apunte que resulta preceptivo mencionar se refiere a la influencia de la reforma constitucional, de 18 de junio de 2008, sobre el régimen sancionador municipal y las consecuencias que dicha reforma presenta en la relación en materia concurrente de «seguridad pública».

Hay que mencionar que la misma reforma incide en algunos de los principales aspectos del régimen policial, persecución de delitos e imposición de penas, de tal forma que se ha reformado sustancialmente el proceso penal en México -aunque su efectivo desarrollo requerirá de muchos ajustes en el sistema federal y de las Entidades federativas. Aunado a lo anterior, la mayor parte de los estudios y opiniones doctrinales al respecto están referidos exclusivamente al «nuevo» régimen penal mexicano y han dejado a un lado el estudio sobre el impacto de dicha reforma en el régimen sancionador en general y del municipal en particular.

Por lo que ahora interesa, la reforma constitucional sobre Seguridad y Justicia de 2008, además de los aspectos penales de gran calado también incide en los aspectos municipales, de ahí la reforma a los artículos 21 y $115 \mathrm{CF}$, referidos especialmente al sistema de sanciones y de coordinación de la policía municipal entre el Presidente municipal y la Entidad federativa -a través de la «Ley de Seguridad Pública del Estado» ${ }^{32}$.

La reforma constitucional reitera que la «seguridad pública» es una función a cargo de la Federación, Entidades federativas, Distrito federal y Municipios, es decir, se trata de una materia sobre las que se ejercen facultades concurrentes de todas las entidades jurídico-públicas territoriales que conforman el Estado

32 Artículo 115, fracción VII CF. Adicionado por reforma constitucional de 18 de junio de 2008. 
federal mexicano ${ }^{33}$. En consecuencia, como resulta doctrina jurisprudencial consolidada, a través de la ley federal «el Congreso de la Unión determina las formas y términos» de la concurrencia material ${ }^{34}$. Ahora bien, lo que no se ha definido en este sistema concurrente es la actuación municipal para regular su sistema de infracciones y sanciones así como la relación que éste tiene con un concepto de seguridad pública que presenta dificultades para determinar su contenido y para resolver su colusión con otros bienes, intereses y principios constitucionalmente previstos ${ }^{35}$.

La cuestión a destacar de esta reforma consiste en delimitar los alcances de la nueva redacción del artículo 21: «La seguridad pública es una función a cargo de la Federación, el Distrito federal, los Estados y los Municipios, que comprende la prevención de los delitos; la investigación y persecución para hacerla efectiva, así como la sanción de las infracciones administrativas, en los términos de la ley, en las respectivas competencias que esta Constitución señala» (el subrayado es mío).

Sin duda, la reforma constitucional dirigida especialmente al Derecho penal impacta en el sistema administrativo sancionador y, a mi juicio provoca un relanzamiento o impulso a esta parte especial del Derecho administrativo mexicano, que debería ser aprovechada para configurar un desarrollo propio y moderno.

La reforma indica claramente que el Derecho administrativo sancionador ejerce una función relevante como mecanismo de control de las actividades de los sujetos, en la medida en que convierte a esta rama en una herramienta fundamental de la «seguridad pública» como materia encaminada a garantizar la paz social por medio del ius puniendi del Estado (Derecho penal y Derecho administrativo sancionador $)^{36}$.

En este orden de ideas, lo que conviene distinguir -a efectos de clarificar los alcances de la materia de seguridad pública sobre el régimen administrativo sancionador y de la persecución de los delitos- es el contenido de la misma idea de seguridad pública.

La seguridad pública es un concepto amplio que ha sido delimitado por el Derecho y del que han derivado varios aspectos que deben ser considerados en la adecuada interpretación constitucional. Como ha dicho la doctrina especiali-

\footnotetext{
33 Ver, artículo 21, párrafo IX y artículo 73, fracción XXIII, artículo 115, fracción III h), CF.

34 Novena época, Pleno, Semanario Judicial de la Federación y su Gaceta, XV, enero, 2002, tesis: P./J. 142/2001, pág. 1042, IUS: 187982.

35 Sobre la solución de este tipo de tensiones ver la exposición de RoDRíGUEZ DE SANTIAGO, José María, La ponderación de bienes e intereses en el Derecho administrativo, Madrid, Marcial Pons, 2000, en todo.

36 Sobre esta relación entre ambas ramas del Derecho público ver PAREJO ALFONSO, Luciano, Seguridad pública y policía administrativa de seguridad, Valencia, Tirant lo Blanch, 2008, págs. 17 a 22.
} 
zada $^{37}$, la seguridad pública presenta una doble función, como elemento esencial del Derecho penal («prevención de los delitos; la investigación y persecución para hacerla efectiva», artículo $21 \mathrm{CF}$ ) así como la relativa a la prevención, mantenimiento y protección del orden frente a actividades peligrosas ( así como la sanción de las infracciones administrativas...», mismo artículo $21 \mathrm{CF}$ ).

En el primero de los casos, la CF otorga al Ministerio Público funciones de investigación y ejercicio de la acción penal ante los jueces y tribunales ${ }^{38}$, y pone a los cuerpos policiales (federales, estatales y municipales) bajo su «conducción y mando» (artículo $21 \mathrm{CF}$ ). En el segundo caso, se refiere a asuntos esencialmente administrativo que presenta dos vertientes: material y funcional.

En el ámbito material, la seguridad pública está referida al contenido de la actividad estatal, especialmente, a la acción de intervención y castigo del Estado (lato sensu) para asegurar, reprimir y restaurar el orden público definido en las leyes y normas administrativas, "para lograr los objetivos de ésta, traducidos en libertad, orden y paz pública» ${ }^{39}$, así como la seguridad de los ciudadanos y sus bienes y derechos. En el aspecto funcional, la seguridad pública se refiere a la organización estatal para hacer efectiva la prevención o, en su caso represión de conductas antijurídicas. Está referida especialmente a la conformación y relaciones de los cuerpos policiales federales, estatales y municipales, sobre los que insiste el Sistema Nacional de Seguridad Pública inciso a) del artículo 21 y 115 fracción VII CF y las respectivas leyes (federal y estatales) de coordinación de seguridad pública ${ }^{40}$.

\section{Ampliación constitucional de las figuras de sanción municipal}

Como se ha expuesto anteriormente, antes de la reforma de 2008 los Municipios mexicanos contaban con habilitación constitucional para introducir en sus normas municipales (Bandos de Policía, Bando de Buen Gobierno y Reglamentos, especialmente) algunas sanciones a las infracciones. De tal forma que, por previsión directa de la Constitución federal, todos los Municipios podían utilizar la multa y el arresto hasta por 36 horas por las infracciones a sus normas, sin necesidad de habilitación legal (federal o estatal).

Evidentemente, estas dos figuras sancionadoras resultaban insuficientes para regular el régimen sancionador de los Municipios, de tal forma que otras

\footnotetext{
$37 \mathrm{Al}$ respecto remito al lector a la obra de Luciano Parejo y la bibliografía expuesta en su obra.

38 Una de los contenidos relevantes de la reforma consiste en la posibilidad para que los particulares ejerzan la acción penal directamente ante la autoridad judicial (artículo $21 \mathrm{CF}$ ).

39 Novena época, Pleno, Semanario Judicial de la Federación y su Gaceta, XI, abril, 2000, pág. 557, tesis: P./J. 35/2000, IUS: 192083.

$40 \mathrm{Al}$ respecto ver Novena época, Pleno, Semanario Judicial de la Federación y su Gaceta, XI, abril, 2000, pág. 556, tesis: P./J. 39/2000, IUS: 192079.
} 
figuras de castigo municipal también encuentran sustento en las previstas por las leyes municipales emitidas por cada una de las Entidades federativas.

Ahora bien, dentro del conjunto de reformas constitucionales en materia de seguridad y justicia, se ha previsto que también los Municipios pueden introducir directamente de la Constitución otra nueva figura jurídica de sanción: «trabajo a favor de la comunidad» y se mantiene necesariamente su vinculación a la ley para el resto de posibilidades de castigos municipales.

\section{BIBLIOGRAFÍA}

CAAMAÑo DomíngueZ, Francisco, «Autonomía local y Constitución. Razones para recuperar la causalidad perdida», Anuario del Gobierno Local 2003, Madrid, Fundación Democracia y Gobierno Local/Institut de Dret Públic, 2003.

CASARín LeÓn, Manlio Fabio, La facultad reglamentaria, México, Porrúa-UV, 2003.

GónGORA PIMENTEL, Genaro David, «El reconocimiento del Derecho administrativo sancionador en la jurisprudencia constitucional mexicana», en La Ciencia del Derecho procesal constitucional. Estudios en homenaje a Héctor Fix-Zamudio en sus cincuenta años como investigador del Derecho. Ministerio Público, Contencioso administrativo y actualidad jurídica, Ferrer Mac-Gregor, Eduardo y Zaldívar Lelo de Larrea, Arturo (coords.), t. XII, México, UNAM/Marcial Pons/IMDPC, 2008.

JimÉnEZ DoRAnTES, Manuel, Autonomía municipal y planeamiento urbanístico, México, Fontamara, 2007.

LAREnZ, Karl, Metodología de la Ciencia del Derecho, 2. a edición, Rodríguez Molinero, M., (trad.), Bacelona, Ariel, 2001.

LÓPEZ OlverA, Miguel Alejandro, Tratado de la facultad reglamentaria, México, Porrúa, 2007.

MERKL, Adolfo, Teoría general del Derecho administrativo, Granada, Comares, 2004.

PAREJo Alfonso, Luciano, Seguridad pública y policía administrativa de seguridad, Valencia, Tirant lo Blanch, 2008.

PosadA, Aldolfo, Tratado de Derecho administrativo. Según las teorías filosóficas y la legis-

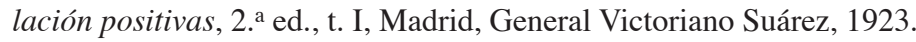

RodrígueZ DE SANTIAgo, José María, La ponderación de bienes e intereses en el Derecho administrativo, Madrid, Marcial Pons, 2001.

Roldán Xopa, José, Derecho administrativo, México, Oxford, 2008.

SANTAMARÍA PASTOR, Juan Alfonso, Principios de Derecho administrativo general, t. I, Madrid, Iustel, 2005.

SCHMIDT-ASSMANN, Eberhard, La teoría general del Derecho administrativo como sistema, Bacigalupo, Mariano, et. al., (trads.), Madrid, Marcial Pons, 2003. 